\title{
Isolation and Characterization of a Drought-Tolerant Cyanobacterium, Nostoc sp. HK-01
}

\author{
Hiroshi KATOH ${ }^{1}$, YOKO ShigA ${ }^{1}$, YUKA NAKAHIRA ${ }^{1}$ and MASAYUKI OHMORI ${ }^{1 *}$ \\ ${ }^{1}$ Department of Life Sciences (Biology), University of Tokyo, Komaba 3-8-1, Meguro, Tokyo 153-8902, Japan
}

(Received January 15, 2003-Accepted April 21, 2003)

A cyanobacterial strain was isolated from cyanobacterial crusts taken from soil in Hyogo Prefecture, Japan and identified as a Nostoc species. This Nostoc strain is drought-tolerant, and its cells differentiated into a particular type, hormogonia, under dark and nutrient-poor conditions. The strain grows well in a liquid medium with a simple nutrient composition that was originally developed for the cultivation of symbiotic Nostoc. The maximum growth rate was attained at $\mathrm{pH}$. The DNA sequences of the 16S rRNA region and trnL(UAA)-intron region were determined to classify this Nostoc species. The trnL(UAA)-intron sequence was homologous to a symbiotic Nostoc, and also to some extent to Anabaena sp. PCC 7120. This cyanobacterium, named Nostoc sp. HK-01, is promising as an improver of arid and nutrient-poor soils.

Key words: cyanobacterium, drought-tolerance, hormogonia, Nostoc

Cyanobacteria of the genus Nostoc are found on every continent on earth in a wide range of terrestrial and aquatic ecosystems. Although numerous strains of Nostoc have been identified, only a few Nostoc species have been characterized in detail ${ }^{4}$. Nostoc commune is a well-known, terrestrial and highly drought-tolerant cyanobacterium ${ }^{12)}$, and desiccated $N$. commune has been shown to survive for almost 100 years ${ }^{1)}$. Desiccated $N$. commune exhibits a rapid recovery of photosynthetic activity, attaining almost half of the maximum level within $1 \mathrm{~h}$ of rewetting ${ }^{16}$. The Nostoc species are thought to be very useful for agricultural applications, their $\mathrm{N}_{2}$-fixing activity in particular contributing greatly to improving the quality of nutrient-poor soils. However, isolation and cultivation techniques for terrestrial cyanobacteria are poorly established.

Sequence analysis of genes encoding the small-subunit of ribosomal RNA (16S rDNA) is currently the most promising approach to the phylogenetic classification of cyanobacteria $^{20)}$. The sequence of the $\operatorname{trnL}(\mathrm{UAA})$ intron (group I intron) is also well used for identifying cyanobacterial taxonomic levels ${ }^{11,20,21)}$. Combining these two methods

\footnotetext{
* Corresponding author; E-mail: chomori@mail.ecc.u-tokyo.ac.jp, Tel: +81-3-5454-6631, Fax: +81-3-5454-4333
}

of sequence analysis, cyanobacteria are classified with high confidence.

In this study, we succeeded in isolating a drought-tolerant Nostoc sp. and cultivated it axenically. The phylogenetic position of the isolated Nostoc was determined from the sequences of the $16 \mathrm{~S}$ rDNA and $\operatorname{trn} L(\mathrm{UAA})$ intron.

\section{Materials and Methods}

\section{Cultivation media}

For isolation, an agar containing a 20 -fold dilution of DTN medium which was developed by Castenholz and modified later by Mühlenhoff and Chauvat was used ${ }^{2,9)}$. The DTN medium contains in one liter; $0.19 \mathrm{~g} \mathrm{Na}_{2}$ EDTA, $52.5 \mathrm{mg} \mathrm{MgSO}_{4}, 0.1 \mathrm{~g} \mathrm{KNO}_{3}, 0.7 \mathrm{~g} \mathrm{NaNO}_{3}, 0.122 \mathrm{~g}$ $\mathrm{NaH}_{2} \mathrm{PO}_{4} \cdot 2 \mathrm{H}_{2} \mathrm{O}, 42 \mathrm{mg} \mathrm{CaCl} 2,1 \mathrm{mg} \mathrm{FeCl}_{3} \cdot 6 \mathrm{H}_{2} \mathrm{O}, 5 \mathrm{mg}$ $\mathrm{NH}_{4} \mathrm{Cl}, 0.1 \mathrm{~g} \mathrm{Na} \mathrm{S}_{2} \mathrm{O}_{3} \cdot 5 \mathrm{H}_{2} \mathrm{O}, 83 \mathrm{mg} \mathrm{NaHSO}, 0.42 \mathrm{~g}$ $\mathrm{NaHCO}_{3}$, and $0.5 \mathrm{ml}$ trace elements $\left(0.5 \mathrm{ml} \mathrm{H}_{2} \mathrm{SO}_{4}, 0.5 \mathrm{~g}\right.$ $\mathrm{H}_{3} \mathrm{BO}_{4}, 2.28 \mathrm{~g} \mathrm{MnSO}_{4}-5 \mathrm{H}_{2} \mathrm{O}, 0.5 \mathrm{~g} \mathrm{ZnSO}_{4}-7 \mathrm{H}_{2} \mathrm{O}, 25 \mathrm{mg}$ $\mathrm{CuSO}_{4}-5 \mathrm{H}_{2} \mathrm{O}, 25 \mathrm{mg} \mathrm{Na} \mathrm{MoO}_{4}-2 \mathrm{H}_{2} \mathrm{O}, 45 \mathrm{mg} \mathrm{CoCl} \mathrm{Cl}_{2}-6 \mathrm{H}_{2} \mathrm{O}$, $19 \mathrm{mg} \mathrm{NiSO} 4\left(\mathrm{NH}_{4}\right) \mathrm{SO}_{4}-6 \mathrm{H}_{2} \mathrm{O}$ and $4 \mathrm{mg} \mathrm{NaSeO} 4$ in one liter ${ }^{2)}$ and $8 \mathrm{mM}$ Tricine-NaOH (pH 8.0). A medium developed by Watanabe and Kiyohara ${ }^{19)}$ was used for the liquid culture. The medium contains in one liter; $0.125 \mathrm{~g} \mathrm{~K}_{2} \mathrm{HPO}_{4}$, 
$0.1 \mathrm{~g} \mathrm{KNO}_{3}, 0.275 \mathrm{~g} \mathrm{MgSO}_{4} \cdot 7 \mathrm{H}_{2} \mathrm{O}, 50 \mathrm{mg} \mathrm{CaCl}$, $50 \mathrm{mg}$ $\mathrm{NaCl}, 4 \mathrm{mg} \mathrm{FeSO} \cdot \cdot 7 \mathrm{H}_{2} \mathrm{O}$, and $1 \mathrm{ml}$ of trace elements $\mathrm{A}_{5}$ (2.86 $\mathrm{g} \mathrm{H}_{3} \mathrm{BO}_{3}, 1.81 \mathrm{~g} \mathrm{MnCl}_{2} \cdot 4 \mathrm{H}_{2} \mathrm{O}, 0.22 \mathrm{~g} \mathrm{ZnSO}_{4} \cdot 7 \mathrm{H}_{2} \mathrm{O}, 80$ mg $\mathrm{CuSO}_{4} \cdot 5 \mathrm{H}_{2} \mathrm{O}, 21 \mathrm{mg} \mathrm{Na} \mathrm{MoO}_{4}$ and $20 \mu \mathrm{l}$ concentrated sulfuric acid in one liter). This medium is referred to herein

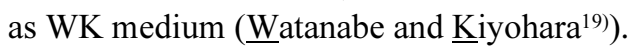

\section{Isolation and purification of Nostoc sp.}

Crusts of cyanobacteria were collected at the Harima Science Garden City Campus of Himeji Institute of Technology, Hyogo Prefecture, Japan ${ }^{16)}\left(134.5^{\circ} \mathrm{E}, 35^{\prime}\right)$. The crusts were dried for a week at $25^{\circ} \mathrm{C}$ in dark and stored in darkness at room temperature. These crusts were soaked with sterile MQ-water for 1 day and washed twice with sterile water. Wetted crusts were ground with a mortar and pestle and then spread on a $1 / 20$ DTN agar plate. They were grown

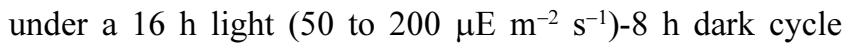
from 25 to $30^{\circ} \mathrm{C}$ for about 1 month. The colonies of Nostoc sp. excreting polysaccharide were cultured on another $1 / 20$ DTN plate. When a layer of extracellular polysaccharide encompassed the Nostoc, they were washed with sterile water and then cultured using kanamycin $\left(5 \mu \mathrm{g} \mathrm{ml}^{-1}\right)$ to reduce bacterial contaminants. Finally, the pure Nostoc sp. named Nostoc sp. strain HK-01 was successfully isolated. Strain HK-01 was kept under a $16 \mathrm{~h}$ light (20 to $50 \mu \mathrm{E} \mathrm{m} \mathrm{m}^{-2}$ $\left.\mathrm{s}^{-1}\right)-8 \mathrm{~h}$ dark cycle at $22^{\circ} \mathrm{C}$.

A test for purity of the culture was carried out as described by Rippka ${ }^{13)}$. An aliquot of cultured cells was grown in DTN medium supplemented with $0.5 \%(\mathrm{w} / \mathrm{v})$ glucose at $37^{\circ} \mathrm{C}$ for 3 days in room light, and then at $30^{\circ} \mathrm{C}$ for 5 days in the dark. An aliquot of this culture was propagated on an M9 plate containing $0.5 \%(\mathrm{w} / \mathrm{v})$ glucose and $0.05 \%(\mathrm{w} / \mathrm{v})$ casamino acid at $30^{\circ} \mathrm{C}$ for 2 weeks in the dark, and then contamination by other bacteria was checked with a microscope.

\section{Drought-tolerant test}

Nostoc sp. HK-01 was grown on the plate containing $1 / 20$ DTN under light $\left(40 \mu \mathrm{E} \mathrm{m}^{-2} \mathrm{~s}^{-1}\right)$ at $30^{\circ} \mathrm{C}$ for 2 weeks. Then it was dried for a week under room lights at $25^{\circ} \mathrm{C}$ and $30 \%$ relative humidity, and stored for 3 months under room lights at $25^{\circ} \mathrm{C}$. The dried strain was soaked with sterile water for $10 \mathrm{~min}$, streaked on a $1 / 20 \mathrm{DTN}$ plate and incubated under light $\left(40 \mu \mathrm{E} \mathrm{m}^{-2} \mathrm{~s}^{-1}\right)$ at $30^{\circ} \mathrm{C}$.

\section{Hormogonia differentiation}

Nostoc sp. HK-01 was streaked on DTN and 1/20 DTN plates and cultivated under continuous light (40 to $50 \mu \mathrm{E}$ $\left.\mathrm{m}^{-2} \mathrm{~s}^{-1}\right)$ at $30^{\circ} \mathrm{C}$ for 4 days. These plates were then placed in the dark for 2 days, and hormogonia were found during the dark period. They were cultivated under continuous light again.

\section{Growth of Nostoc sp. HK-01 in liquid medium}

To find an adequate medium for optimum growth, Nostoc sp. HK-01 was grown in DTN medium, 4-fold and 20-fold diluted DTN medium, and WK medium under continuous light $\left(40 \mu \mathrm{E} \mathrm{m}^{-2} \mathrm{~s}^{-1}\right)$ at $30^{\circ} \mathrm{C}$ by shaking at $120 \mathrm{rpm}$. To examine the optimum $\mathrm{pH}$ for growth, the $\mathrm{pH}$ of the WK medium was adjusted with $5 \mathrm{mM}$ 2-morpholinoethanesulfonic acid (MES)-NaOH (pH 6.0), N-2-hydroxyethylpiperazine$\mathrm{N}^{\prime}$-2-ethanesulfonic acid (HEPES)-NaOH (pH 7.0), N-tris(hydroxymethyl)methyl-2-aminoethanesulfonic acid (TES)$\mathrm{NaOH}$ (pH 8.0) or N-cyclohexyl-2-aminoethanesulfonic acid (CHES)-NaOH (pH 9.0, 10.0). The chlorophyll concentration extracted by methanol was measured at $665 \mathrm{~nm}$ and then calculated with $A_{665} \quad 1=13.42 \mu \mathrm{g} \mathrm{Chl} / \mathrm{ml}^{7}$.

\section{DNA sequencing}

DNA was extracted from Nostoc sp. HK-01 according to the method of Murray and Thompson ${ }^{10)}$ using cetyltrimethylammonium bromide (CTAB) to reduce contamination by polysaccharide. PCR amplifications were performed with a Gene Amp ${ }^{\circledR}$ PCR System 9700 (Applied Biosystems, USA) using primers for $16 \mathrm{~S}$ rDNA (5'-AGAGTTTGATCCTGGCTC-3' and 5'-AAAGGAGGTGATCCAGCC-3'), tRNA-Leu (UAA)(5'-TGTGGCGGAATGGTAGACGCTAC-3', and 5'-GGGTGGAGGGACTTGA-3') ${ }^{21)}$. The $1.4 \mathrm{kbp}(16 \mathrm{~S}$ rD$\mathrm{NA}$ ) and $0.3 \mathrm{kbp}$ (trnL(UAA)-intron) nucleotide sequences were directly determined with a capillary DNA sequencer (model 310S, PE-biosystems, USA) using a Big Dye terminator DNA sequencing kit (PE-biosystems). The primers 5'AACCTCTTTTCTCAGGGA-3' and 5'-GTCTCTCTAGAGTGCCCA-3' were used to determine the inner sequence of the $16 \mathrm{~S}$ rRNA.

\section{S rDNA phylogenetic analysis}

DNA sequences corresponding to the complete or near complete 16S rRNA gene were aligned using the program CLUSTAL $\mathrm{W}^{18)}$, and finally refined visually. The positions with gaps and undetermined and ambiguous sequences were removed for subsequent phylogenetic analyses. Phylogenetic analyses were performed by the neighbor-joining $(\mathrm{NJ})^{14)}$ and maximum-parsimony (MP) methods following Sano et al. ${ }^{15)}$. We used PAUP ver. $4^{17)}$ for MP analyses. The most parsimonious trees were found by the heuristic search option using 1,000 replications of random sequence addition with Tree Bisection-Reconnection (TBR) branch swa- 
Table 1. Nucleotide sequences used in this study.

a) $16 \mathrm{~S}$ rDNA sequence

\begin{tabular}{|c|c|}
\hline strain & accession no. \\
\hline Nostoc sp. HK- $01^{\text {a }}$ & AB085687 \\
\hline Anabaena (Nostoc) sp. PCC 7120 & AP003598 \\
\hline Anabaena variabilis IAM M-3 & AB016520 \\
\hline Anabaena variabilis NIES23 & AF247593 \\
\hline Cylindrospermum sp. PCC 7417 & CSP133163 \\
\hline Nostoc punctiforme PCC 73102 & AF027655 \\
\hline Nostoc sp. 152 & NSP133161 \\
\hline Nostoc sp. ATCC 53789 & AF062638 \\
\hline Nostoc sp. AWT 203 & AF317630 \\
\hline Nostoc sp. DM103 & NDM344563 \\
\hline Nostoc sp. GSV224 & AF062637 \\
\hline Nostoc sp. PCC 9709 & AF027654 \\
\hline Nostoc sp. TDI\#AR94 & AF027653 \\
\hline Synechococcus sp. PCC 6301 & X03538 \\
\hline Synechocystis sp. PCC 6803 & D64000 \\
\hline
\end{tabular}

${ }^{a}$ Isolated Nostoc in this study

b) $\operatorname{trn} L$ (UAA) intron sequence

\begin{tabular}{ll}
\hline \multicolumn{1}{c}{ strain } & accession no. \\
\hline Nostoc sp. HK-01 ${ }^{\text {a }}$ & $\mathrm{AB} 085686$ \\
Anabaena (Nostoc) sp. PCC 7120 & $\mathrm{AP003597}$ \\
Nostoc commune strain DRH1 & $\mathrm{AF} 204090$ \\
Nostoc commune UTEX584 & $\mathrm{AF} 204098$ \\
Nostoc punctiforme PCC 73102 & $\mathrm{NSU} 83254$ \\
Nostoc sp. 'Peltigera aphthosa' sample 1 & $\mathrm{AF} 055655$ \\
Nostoc sp. TCS-2001/2 & $\mathrm{NSP} 422008$
\end{tabular}

pping. Bootstrap analysis ${ }^{3)}$ with 1,000 replications was performed.

\section{Nucleotide sequence accession number}

The nucleotide sequences of the $\operatorname{trn} L(\mathrm{UAA})$ intron and 16S rDNA for isolated Nostoc have been registered under DDBJ accession number AB085686 and AB085687, respectively. The accession numbers of nucleotide sequences used in this study are shown in Table 1.

\section{Results}

\section{Isolation and purification of Nostoc $s p$. HK-OI}

The components of the culture medium, as well as temperature and light conditions, needed to isolate and cultivate the cyanobacterium were determined. After many trials, Nostoc sp. HK-01 was successfully isolated using a lowconcentration inorganic-nutrient $(1 / 20 \mathrm{DTN})$ plate. The iso-

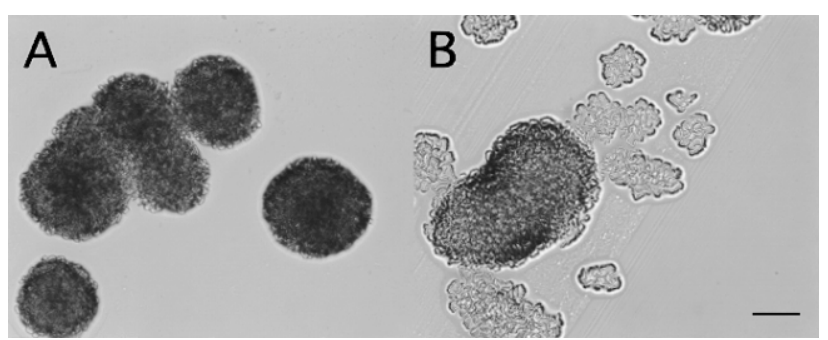

Fig. 1. Microphotographs of isolated Nostoc sp. HK-01 grown on 1/20 DTN (panel A) and DTN (panel B) plates. Scale bar=100 $\mu \mathrm{m}$.

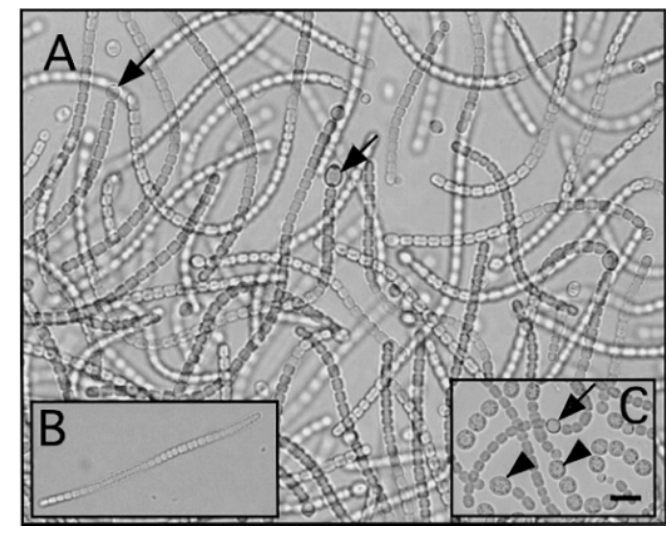

Fig. 2. Microphotographs of the isolated Nostoc sp. HK-01 cells. Panel A: vegetative cells and heterocysts (arrows), panel B: hormogonium, panel $\mathrm{C}$ : akinetes (arrowheads) and heterocyst (arrow). Scale bar $=10 \mu \mathrm{m}$.

lated Nostoc strain grew well on a 1/20 DTN plate and dense colonies were obtained (Fig. 1A). On the other hand, the colonies grown on a high-concentration inorganic-nutrient (DTN) plate were sparse, and grew more slowly than those grown on the $1 / 20$ DTN plate (Fig. 1B). These findings suggest that a low-concentration of inorganic-nutrient is desirable for the growth of strain HK-01 on the plate.

As shown in Fig. 2A, the isolated cyanobacterium is filamentous and the vegetative cells are 3 to $4 \mu \mathrm{m}$ in length and 2 to $3 \mu \mathrm{m}$ in width. This strain has differentiated cell types: heterocysts (Fig. 2A and 2C, arrows), motile hormogonia (Fig. 2B), and akinetes (Fig. 2C, arrowhead), and these features are characteristics of the genus Nostoc (4).

\section{Drought-tolerance test}

To investigate drought-tolerance, strain HK-01 was first subjected to dehydration for at least 3 months, and then rewetted and cultured on a $1 / 20 \mathrm{DTN}$ plate. In terms of growth rate and the number of colonies, the rewetted HK-01 


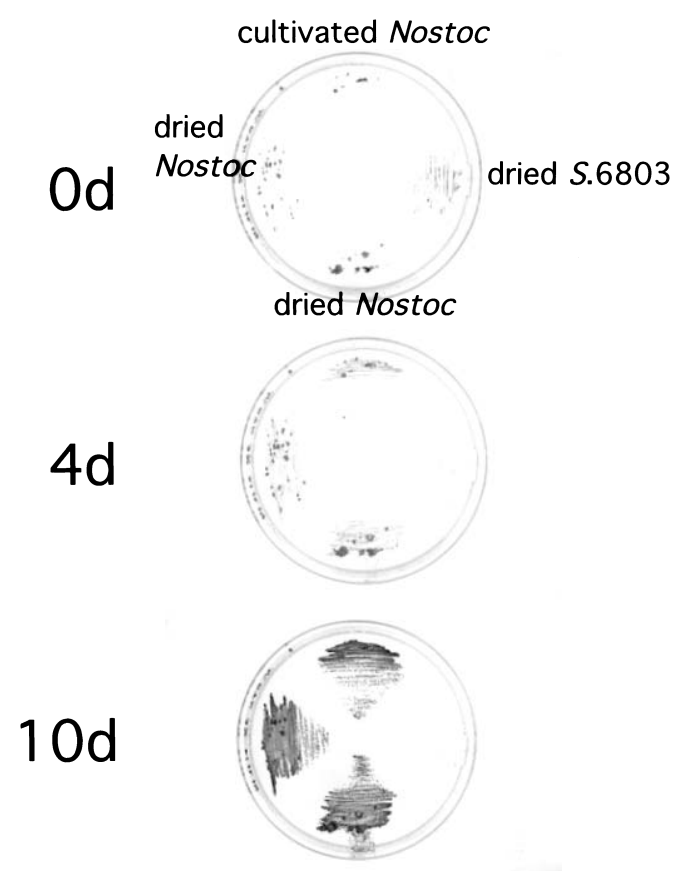

Fig. 3. Drought test for isolated Nostoc sp. strain HK-01. Wet cells of the isolated strain HK-01 (cultivated Nostoc), and desiccated cells of the same strain (dried Nostoc) and of Synechocystis sp. PCC 6803 (dried S. 6803) were grown on a 1/20 DTN plate.

differed little from the non-dried, cultivated form (Fig. 3), indicating that the strain is drought resistant.

\section{Hormogonia differentiation}

Strain HK-01 cells differentiated into motile hormogonia under the previously mentioned nutrient and/or light condi-

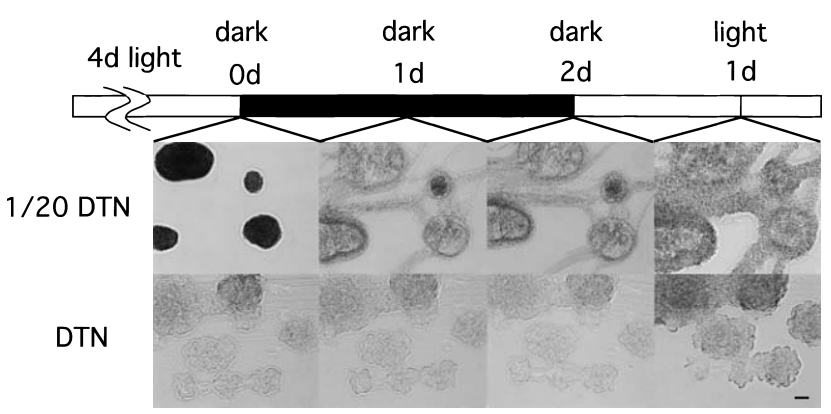

Fig. 4. Effects of nutrients and light on hormogonia differentiation. Scale bar $=100 \mu \mathrm{m}$.

tions (Fig. 4). The newly streaked cells were pre-cultured under light for 4 days to exclude the influence of the transfer to the new medium, as reported previously,12). On the plate with low-concentration inorganic-nutrient $(1 / 20$ DTN), more than $95 \%$ of strain HK-01 cells formed hormogonia within $12-24 \mathrm{~h}$ of cultivation in the dark. These hormogonia could not change into original vegetative cells in the dark, but could under light. On the other hand, this differentiation did not occur on the plate with high-concentration inorganic-nutrient (DTN). It was confirmed that the differentiation into hormogonia requires darkness and a low nutrient concentration.

\section{Growth of Nostoc sp. HK-01 in liquid culture}

To find a medium that sustains the optimum growth of strain HK-01 in the liquid medium, variously diluted DTN media (Fig. 5A) were investigated but this strain grew very slowly in all of them. Therefore, a medium with a simpler nutrient composition, i.e., WK medium originally devel-
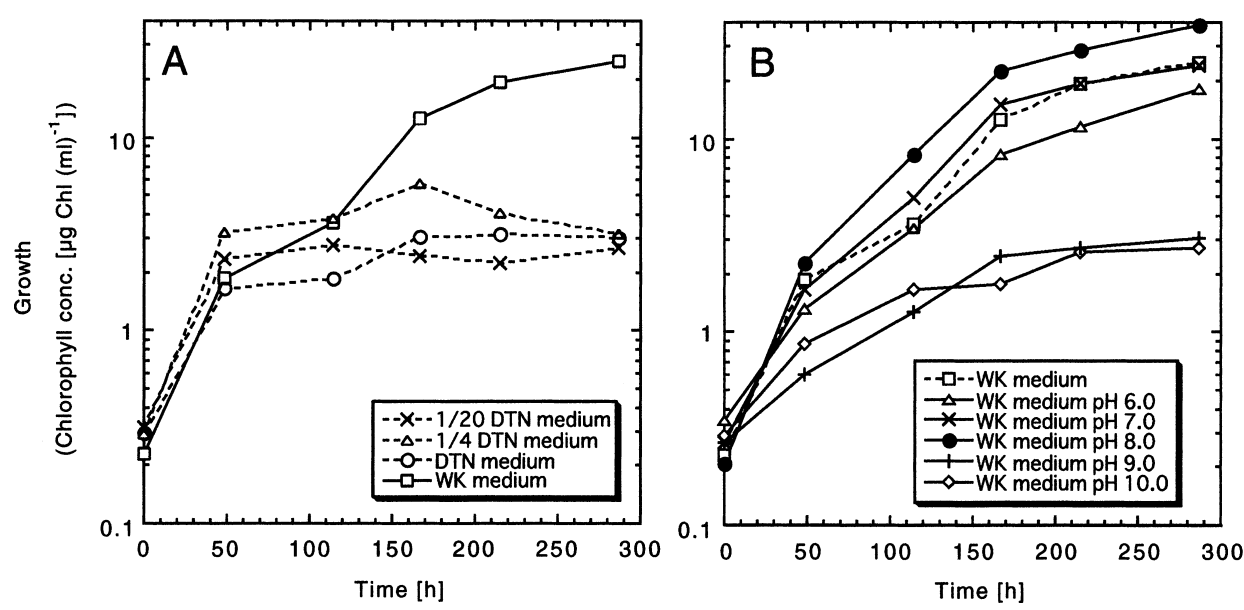

Fig. 5. Growth of the isolated Nostoc sp. HK-01 in liquid media. Cells were grown in various liquid media (panel A), and liquid WK media at various $\mathrm{pH}$ (panel B). 


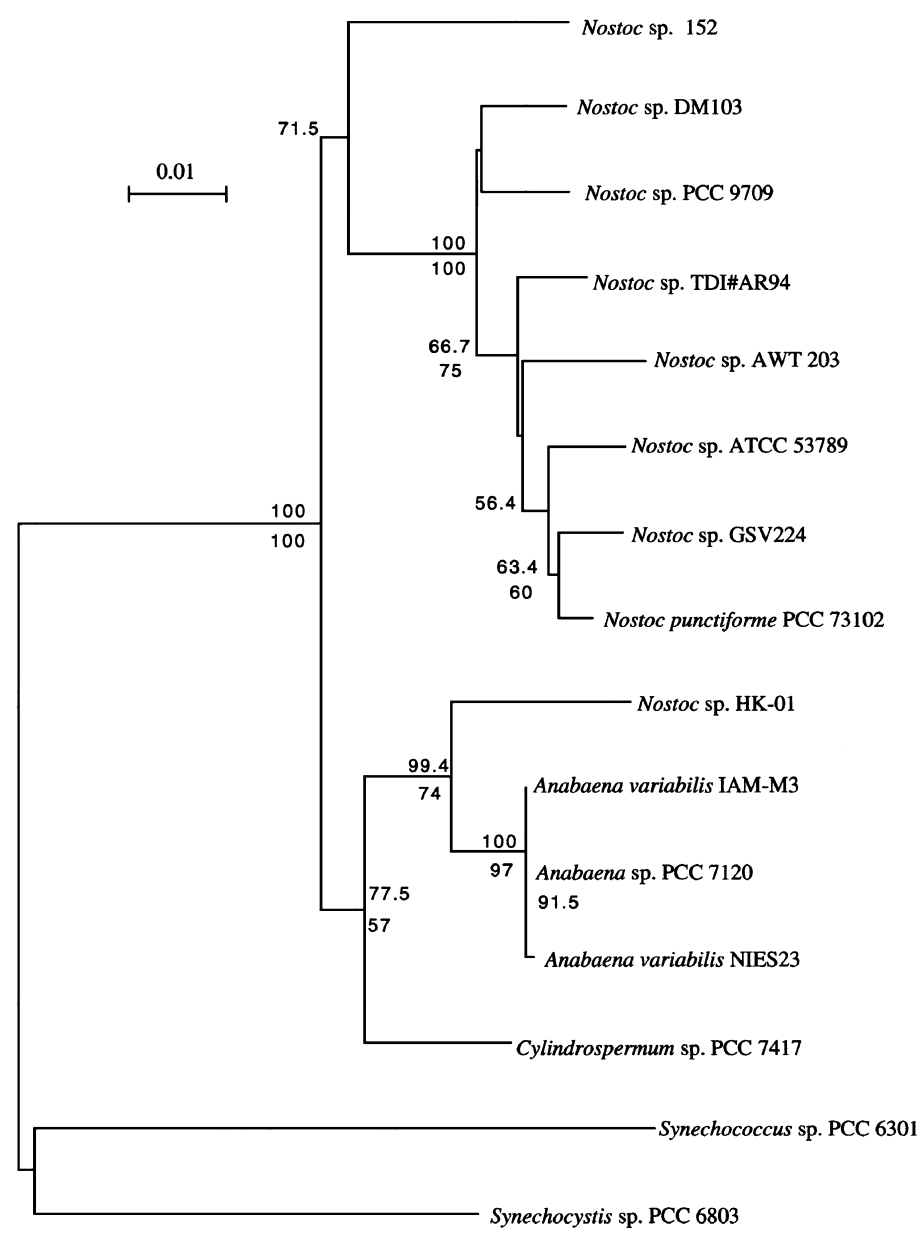

Fig. 6. Distance tree of cyanobacteria constructed on the basis of almost complete 16S rDNA sequences (more than 1300 nucleotides). The phylogenetic tree was constructed using the NJ algorithm as implemented within CLUSTAL W. The root of the tree was determined using the 16S rDNA of Synechocystis sp. PCC 6803 and Synechococcus sp. PCC 6301 as the outgroup. Bootstrap values calculated by the NJ method (above the branches) and MP method (under the branches) are indicated in more than $50 \%$ of 1000 bootstrap replicates.

oped for symbiotic Nostoc ${ }^{19}$, was used. The growth of strain HK-01 cells in the WK medium was obviously better than that in the DTN media (Fig. 5A). The optimum pH for growth was 8.0 (Fig. 5B), which agreed well with that for cyanobacterial growth. Thus, the $\mathrm{pH}$ of the WK medium was adjusted to 8.0 with $5 \mathrm{mM}$ TES-NaOH.

\section{DNA sequencing and phylogenetic analysis}

To determine the genus of strain HK-01, the $16 \mathrm{~S}$ rDNA region was sequenced. The 16S rDNA sequence of this strain was homologous to that of Anabaena and Nostoc. No significant difference was found between the distance tree for the NJ method and that for the MP method. The distance tree for 16S rDNA shows that HK-01 belongs to a cluster of heterocystous cyanobacteria, particularly Anabaena and Nostoc (Fig. 6). The identity of the sequence of strain HK-
01 with Anabaena sp. PCC 7120, Anabaena variabilis IAM M-3 (same as PCC7118), Anabaena variabilis NIES23 and Nostoc punctiforme was $97.4 \%, 97.3 \%, 97.3 \%$ and $93.7 \%$, respectively. To further identify the phylogenetic position of strain HK-01, the trnL(UAA)-intron region, which has been used to classify species within the family Nostoc ${ }^{11,21)}$, was determined. The conserved region of the $\operatorname{trn} L(\mathrm{UAA})-$ intron shows that HK- 01 belongs to the cluster of Anabaena and Nostoc. The alignment of DNA sequences of the socalled hypervariable region ${ }^{21)}$ shows that the sequence of HK-01 is highly homologous to that of symbiotic Nostoc (Fig. 7). It was also shown that the hypervariable region of another drought-tolerant cyanobacterium, Nostoc commune, was $15 \mathrm{bp}$ shorter than that of HK-01. On the other hand, the sequence of variable region I in HK-01 was somewhat different from that in other Nostoc species (Fig. 7). 
media was the concentration of nitrate. The concentration of nitrate needed for good growth was between $0.46 \mathrm{mM}$ (1/20 DTN plate) and $0.99 \mathrm{mM}$ (WK medium), although strain HK-01 could grow without a nitrogen source (data not shown). A high concentration of nitrate $(9.23 \mathrm{mM}$, DTN plate) was inhibitory to growth (data not shown).

The 16S rDNA and trnL(UAA) intron sequence analyses indicate that strain HK-01 is part of the Nostoc cluster. The profile of the phylogenetic tree based on the 16S rDNA sequence was very similar to that based on DNA-DNA hybridization (4). The phylogenetic tree of $16 \mathrm{~S}$ rDNA implies that HK-01 belongs to the Cluster 3 Nostoc (4), which include Anabaena sp. PCC 7120. The bootstrap values of 99.4\% (NJ method) and 74\% (MP method) imply that the clade including Nostoc sp. HK-01 is the same as the clade of Anabaena sp. PCC7120 and Anabaena variabilis. On the other hand, strain HK-01 is distant from Nostoc punctiforme PCC 73102, a Cluster 1 Nostoc (4). In spite of its sequence similarity to a symbiotic Nostoc, HK-01 is non-symbiotic and makes extracellular polysaccharides like non-symbiotic Nostoc commune. Taking these matters into account, it is concluded that Nostoc sp. HK-01 is a new species that can be classified as a Cluster 3 Nostoc very similar to Anabaena sp. PCC 7120.

\section{Acknowledgments}

This work was supported by a grant from Bio-oriented Technology Research Advancement Institution, Japan.

\section{References}

1) Cameron, R.E. 1962. Species of Nostoc vaucher occurring in the Sonoran desert in Arizona. Trans. Amer. Microsc. Soc. 81: 379384.

2) Castenholz, R.W. 1988. Culturing Methods for Cyanobacteria p. 68-93. In L. Packer and A.N. Glazer (ed.), Methods in Enzymology. vol. 167.

3) Felsenstein, J. 1985. Confidence limits on phylogenies: an approach using the bootstrap. Evolution 39: 783-791.

4) Herdman, M., R.W. Castenholz and R. Rippka. 2001. Formgenus VIII. Nostoc Vaucher 1803. p. 575-580. In D.R. Boone and R.W. Castenholz (ed.), Bergey's Manual of Systematic Bacteriology, 2nd Ed. Vol. 1. Springer-Verlag, New York.

5) Herdman, M. and R. Rippka. 1988. Cellular differentiation: hormogonia and Baeocytes. p. 232-242. In L. Packer and A.N. Glazer (ed.), Methods in Enzymology. vol. 167.
6) Lazaroff, N. 1973. Photomorphogenesis and nostocacean development. p. 279-319. In N.G. Carr and B.A. Whitton (ed.), The Biology of Blue-Green Algae. Blackwell Scientific Publications, Oxford.

7) Mackinney, G. 1941. Absorption of light by chlorophyll solutions. J. Biol. Chem. 140: 315-322.

8) Tandeau de Marsac, N. 1994. Differentiation of hormogonia and relationships with other biological processes. p. 825-842. In D.A. Bryant (ed.), The Molecular Biology of Cyanobacteria. Kluwer Academic Publishers, Netherlands.

9) Mühlenhoff, U. and F. Chauvat. 1996. Gene transfer and manipulation in the thermophilic cyanobacterium Synechococcus elongatus. Mol. Gen. Genet. 252: 93-100.

10) Murray, M.G. and W.F. Thompson. 1980. Rapid isolation of high molecular weight plant DNA. Nucleic Acids Res. 8: 4321-4325.

11) Paulsrud, P. and P. Lindblad. 1998. Sequence variation of the tRNA-Leu intron as a marker for genetic diversity and specificity of symbiotic cyanobacteria in some lichens. Appl. Environ. Microbiol. 64: 310-315.

12) Potts, M. 2000. Nostoc. p. 465-504. In B.A. Whitton and M. Potts (ed.), The Ecology of Cyanobacteria. Their Diversity in Time and Space. Kluwer Academic Publishers, Netherlands.

13) Rippka, R. 1988. Isolation and purification of cyanobacteria. p. 3-27. In L. Packer and A.N. Glazer (ed.), Methods in Enzymology. vol. 167.

14) Saitou, N. and M. Nei. 1987. The neighbor-joining method: a new method for reconstructing phylogenetic trees. Mol. Biol. Evol. 4: 406-425.

15) Sano, R., M. Takamiya, M. Ito, S. Kurita and M. Hasebe. 2000. Phylogeny of the lady fern group, tribe Physematieae (Dryopteridaceae), based on chloroplast $r b c L$ gene sequences. Mol. Phylogenet. Evol. 15: 403-413.

16) Satoh, K., M. Hirai, J. Nishio, T. Yamaji, Y. Kashino and H. Koike. 2002. Recovery of photosynthetic systems during rewetting is quite rapid in a terrestrial cyanobacterium, Nostoc commune. Plant Cell Physiol. 43: 170-176.

17) Swofford, D.L. 2001. PAUP*: Phylogenetic Analysis Using Parsimony (* and Other Methods) Version 4., Sinauer Associates, Sunderland, Massachusetts.

18) Thompson, J.D., D.G. Higgins and T.J. Gibson. 1994. CLUSTAL W: improving the sensitivity of progressive multiple sequence alignment through sequence weighting, position specific gap penalties and weight matrix choice. Nucleic Acids Res. 22: 46734680 .

19) Watanabe, A. and T. Kiyohara. 1963. p. 189-196. Symbiotic blue-green algae of lichens, liverworts and cycads. In Studies on Microalgae and Photosynthetic Bacteria, (special issue of Plant Cell Physiol.).

20) Wilmotte, A. 1994. Molecular evolution and taxonomy of cyanobacteria. p. 1-25. In D.A. Bryant (ed.), The Molecular Biology of Cyanobacteria. Kluwer Academic Publishers, Netherlands.

21) Wright, D., T. Prickett, R.F. Helm and M. Potts. 2001. Form species Nostoc commune (Cyanobacteria). Int. J. Syst. Evol. Microbiol. 51: 1839-1852. 